\title{
Correction to: In Situ Analysis of Nickel Uptake from Foliar Application in Pecan Using Instrumental $\mu$ XRF Analysis
}

\author{
Jessica Bezerra de Oliveira ${ }^{1}$. José Lavres ${ }^{1}$. Antony van der Ent ${ }^{2}$
}

Published online: 16 November 2021

(c) The Author(s) under exclusive licence to Sociedad Chilena de la Ciencia del Suelo 2021

\section{Correction to: Journal of Soil Science and Plant Nutrition https://doi.org/10.1007/s42729-021-00599-6}

Due to an error during the production process, corrections in Table 1 (to correct for dilution factor and units) were wrongly implemented. In the article originally published, Table 1 contains both the corrected and erroneous values mixed-up.

The original article has been corrected.

Publisher's Note Springer Nature remains neutral with regard to jurisdictional claims in published maps and institutional affiliations.

The original article can be found online at https://doi.org/10.1007/ s42729-021-00599-6.

Antony van der Ent

a.vanderent@uq.edu.au

1 Centro de Energia Nuclear Na Agricultura, Universidade de São Paulo, São Paulo, Brazil

2 Centre for Mined Land Rehabilitation, Sustainable Minerals Institute, The University of Queensland, Brisbane, Queensland, Australia 